\title{
陈晓亚：能否办好期刊取决于大家的信心和努力
}

安瑞

\section{Xiao-Ya Chen: Confidence and efforts lead to the success of the journal}

Rui An

doi: 10.1360/TB-2020-0740

陈晓亚, 植物生理学家, 中国科学院院士、发展中国 家科学院院士, 中国科学院 (以下简称“中科院”)分子植物 科学卓越创新中心/上海植物生理生态研究所研究员、博士 生导师, 中科院上海辰山植物科学研究中心主任, 兼任上 海辰山植物园园长, 主要从事植物次生代谢调控及表皮细 胞发育研究. 2008年起至今担任《中国科学: 生命科学》编 委; 2014 2017年担任Science Bulletin(《科学通报》英文版) 主编, 2018年起担任顾问委员会委员.

2020年, 《中国科学》《科学通报》(以下简称“两刊”) 迎来创刊70周年. 《中国科学》杂志社专访陈晓亚院士, 讲 述他与 “两刊”的缘分和故事, 共同探讨中国科技期刊的发 展问题.

\section{“两刊”在我心里留下了美好、崇高的印象}

今年, 恰逢“两刊”创刊70周年, 可否回忆一下您最 初对“两刊”的印象以及后来发表文章的经历?

陈晓亚: 记得我在南京大学生物学系读大学本科期 间, 大概是 1979 年, 物理系老师在《中国科学》发表了一 篇论文, 一时间成为学校的大新闻. 同学们热烈议论, “两 刊”因此在我心里留下了最初的、也是非常美好、崇高的印 象. 若干年后, 这位物理系教授当选为中科院院士.

1994年, 我结束了在美国普渡大学的博士后研究工作, 回国后到当时的中科院上海植物生理研究所工作. 2000年 开始, 我的研究组陆续在“两刊”发表研究工作和综述、评 论文章(计 17篇). “两刊”为学术交流合作和科学知识普及 提供了极好的平台, 对科研工作者的学术成长发挥了非常 重要的推动作用.

还记得您在“两刊”发表的第一篇论文吗? 当时投稿 是怎样的一种经历和心情?

陈晓亚：1997年, 中科院副院长许智宏先生推荐我到 日本奈良尖端科学技术大学进行了半年访问研究. Yamada 校长和Hashimoto教授是植物次生代谢领域的知名学者, 日本奈良尖端科学技术大学又是刚刚成立, 起点高, 条件 好. 我在奈良除了开展棉酚生物合成途径研究, 还有了深

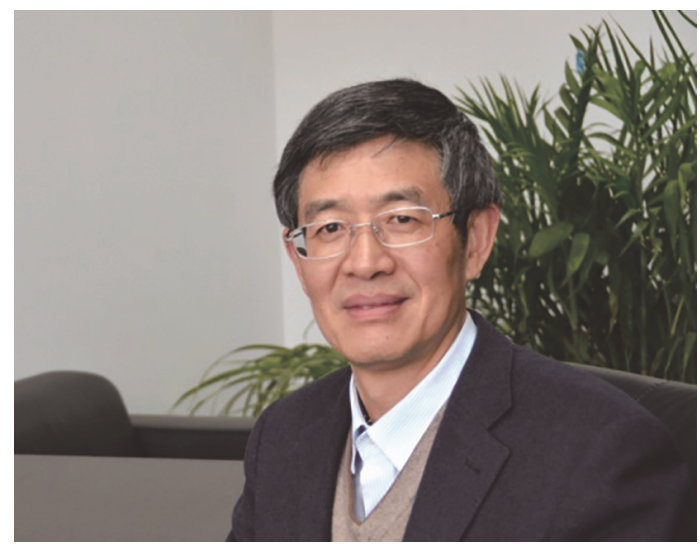

陈晓亚 院士

人交流切磋的机会. 之后, 结合课题组在上海的实验结果, 我们整理了一篇题为 “亚洲棉(+)- $\delta$-杜松烯合成酶基因 $C A D 1-A$ 的分离及其在幼苗中的表达特征分析”的研究论 文. 《中国科学》是我心目中最好的中国科技期刊, 在许 智宏老师的鼓励下, 我们决定将论文投到《中国科学 $C$ 辑: 生命科学》. 2000年, 我们课题组在《中国科学》发表了两 篇研究论文, 一篇是上述棉酚途径酶基因的论文, 另一篇 是和许智宏老师合作的“陆地棉徐-142种子无毛突变体的 比较研究”.

\section{有志者事竟成}

多年来，您担任“两刊”的编委工作，特别是2014 2017年, 您担任了Science Bulletin的主编, 这是这本期 刊发展历史上一个非常重要的时期. 您是如何担任这 本期刊主编的?

陈晓亚：2014年，朱作言总主编找到我，邀请我担任 Science Bulletin的主编. 我了解到当时主办单位中科院已 经明确了以《科学通报》为试点对“两刊”进行深化改革的 要求, 并决定分别设立新一届中文版和英文版编委会, 两 个版本各自分开, 不再对照出版, 以此来推动两个版本各 自更好地发展. 当时《科学通报》中文版已经邀请到高福 
院士担任主编, 并组建了编委会. 我认为这是一件大好事, 对《科学通报》这样具有厚重的历史、同时倾注了很多科 学家心血和感情的期刊来说, 敢于尝试新的办刊模式, 进 行国际化发展探索, 迎来了一个非常好的发展机遇.

然而, 机遇总是与挑战并存. 担任这样一本综合性“老 刊”的主编, 要对期刊进行国际化的定位和思考, 开展全 方位的改革和创新, 并不是一件轻轻松松的事, 一开始我 还是有些紧张. 5 月 30 日, 我参加了中科院召开的《科学通 报》改革工作研讨会. 李静海副院长、朱作言总主编以及 科学传播局、学部工作局和《中国科学》杂志社的相关同 志出席了会议. 会议研讨并认可了《科学通报》分设中、 英文版编委会、英文版变更刊名和刊期等事宜. 这个会议 让我看到了上下同心的支持和改革信心, 好像给我吃了定 心丸, 我对办好这本刊物充满了信心! 那一段时间, 我频 繁从上海到北京, 与杂志社、编辑部的同志交流; 通过电 子邮件不断和执行主编、编辑部沟通编委会组建的细节和 定位目标, 就这样, 担子一挑就是3年多.

您担任主编期间的办刊愿景以及采取的主要措施 是什么?

陈晓亚: 我们当时拟定了一个期刊发展目标, 并作了 5年发展规划: 确定了Chinese Science Bulletin在2015年启 用新刊名Science Bulletin, 改为半月刊, 逐步使其学科内 涵接近国际同类大刊的发展现状, 在稿源、编委、出版发 行国际化方面取得新的突破, 有效提升刊物的国际竞争力 和影响力, 在 3 年左右的时间里, 努力使期刊的主要学术 指标进人国际同类综合性期刊的前 $15 \%$ (影响因子(IF)接近 3 ); 在 5 年左右的时间里, 使其学术指标进人前 $10 \%$ (IF接近 $5)$, 成为国际同类期刊的知名品牌, 也就是后来所说的 “3 年3, 5年5”的目标. 提出这样的目标, 一是我们要树立破 茧成蝶、重新起航的信心和勇气; 二是基于当时《科学通 报》英文版IF只有 1.319 的考虑. 这样一个目标的提出, 我 们也是经过了充分的讨论, 甚至是自我审视和质疑. 讨论 中有执行主编提到: “我们要考虑, 如果IF $>3$, 作者为什么 不投国际上熟悉并广泛发表、引用的国际期刊, 而投 (C)SB? ——我们自己要回答这个问题.”

我想这段对期刊的描述反映了我们当时的办刊愿景: 更名后的Science Bulletin, 将以快速发表自然科学与技术 各领域的原创性研究成果、有洞察力的综述、前瞻性展望 以及对热点科学问题的报道和评论为己任, 致力于提升发 文品质, 增强国际影响力, 使其报道内涵与我国科学发展 态势与水平相适应, 成为国际同类的知名品牌, 促进我国 乃至世界科学技术的传播、交叉与进步.

从刊物的发展现状看, 这些目标有没有实现? 您如 何评价 5 年来Science Bulletin的成长轨迹? 您对 Science Bulletin的未来发展有何建议和期望?

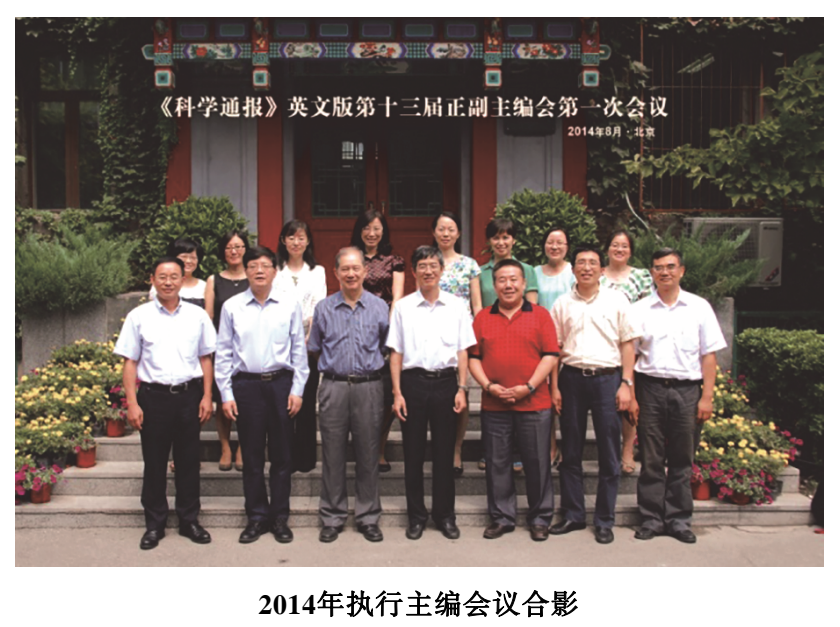

陈晓亚: 非常欣慰的是, 从期刊发展现状来看, 我们 做到了. 经过3年多可以说艰苦卓绝的努力, 2017年, 期刊 获得了更名后的第一个IF为4.093. 现在刊物一直保持跨越 式发展的势头, 其学术影响力得到了越来越多的关注和认 可. Science Bulletin的茁壮成长离不开中科院和学部领导 的关心, 离不开全体编委和编辑部工作人员的辛勤付出, 也离不开广大科研人员的支持. 我认为期刊仍要坚持快速 发表自然科学原创性研究成果, 汇集科技前沿和热点的特 色. 我衷心祝愿Science Bulletin越办越好, 向世界一流综 合性科技期刊奋进!

\section{这是一个团结、温馨、奋进的集体}

在与“两刊”打交道期间，有没有让您印象非常深刻 的人或事?

陈晓亚：2014年8月21日，第一次召开执行主编会议， 我至今仍记忆犹新. 记得那天会议, 我和龙桂鲁、赵宇亮、 牛耀龄、王连洲和赵天寿几位执行主编第一次碰头. 虽然 大多是第一次见面, 但是感觉已然像是老友重逢. 因为之 前通过电子邮件大家已经进行了频繁的沟通交流, 对办好 Science Bulletin已取得了思想上行动上的一致. 会议的过 程也体现了坚定的信心、务实的讨论和立竿见影的行动. 会后, 大家到科学出版社餐厅一起吃午餐. 餐间服务员突 然端来一个生日蛋糕, 这令我非常惊喜. 因为当天恰好也 是我的生日, 大家在这样一个机缘巧合的时间共同为我送 上生日祝福, 我至今难忘.

\section{为“两刊”更加美好的明天而努力奋斗}

近期, 《关于深化改革培育世界一流科技期刊的意 见》给中国期刊定出了明确的发展时间表: 到2035年, 我国科技期刊综合实力跃居世界第一方阵. 您认为要 实现这一目标, 迫切需要解决的问题是什么?

陈晓亚：这个意见的出台对中国科技期刊来说，确是 
迎来了大好的发展机遇. 包括“两刊”在内的中国科技期刊, 应紧紧抓住机遇, 发展好自己. 除了要不断学习国际先进 刊物的成功经验, 也要在实践中不断摸索适合我国科技期 刊的发展之路. 我国科技期刊要大力吸引国内和国外的优 秀科研论文, 强化快速、专业、公正的审稿机制, 进行国 际化的运营管理, 开展丰富多样、深人人心的宣传工作. 在“两刊”工作的期间, 我也深深感受到了大家对办好刊物
的坚定信心和默默奉献、坚持不解的努力，相信我国科技 期刊一定能在国际一流期刊阵营中占有一席之地.

在“两刊”创刊70周年之际, 您对“两刊”有什么寄语 和期望?

陈晓亚：展现创新成果, 鼓励大胆突破, 引领发展潮 流. 为“两刊”更加美好的明天而努力奋斗! 